\title{
First record of the genus Ruffojassa Vader \& Myers, 1996 (Amphipoda, Corophiidea) from Brazilian waters, with description of a new species"
}

Jesser F. Souza-Filho, Ana Maria T. Souza and Maria Teresa Valério-Berardo

(JFSF) Museu de Oceanografia Petrônio Alves Coelho, Universidade Federal de Pernambuco, Laboratório de Carcinologia. Av. Arquitetura, s/n, Cidade Universitária, CEP 50740-550, Recife, Pernambuco, Brazil.E-mail: jesser_fidelis@yahoo.com.br.

(AMTS) Universidade Presbiteriana Mackenzie, São Paulo, Brazil. E-mail: anamabio@mackenzie.br. (MTVB) Instituto Oceanográfico, Universidade de São Paulo, São Paulo, Brazil. E-mail: mariateresa_berardo@yahoo.com.br.

\section{Abstract}

A new species, Ruffojassa petronioi sp. nov., is described from southern Brazilian coast. The new species was collected at $56 \mathrm{~m}$ depth at the coordinates $21^{\circ} 42$ 'S / $40^{\circ} 15^{\prime} \mathrm{W}$ with a mini biological trawl aboard of R.V. Prof. W. Besnard. In this paper we recorded the genus for the first time from Brazilian waters.

Key words: Ischyroceridae, new taxa, Ruffojassa petronioi sp. nov.

\section{Introduction}

The genus Ruffojassa was erected by Vader and Myers (1996) being distinct of Parajassa Stebbing, 1899 mainly by the presence of an accessory flagellum, the shape of coxa 5 and the ornamentations of uropod 3. In that revision, all species of Parajassa, except for $P$. pelagica (Leach, 1814), have been transferred to the genus Ruffojassa, and a new species, $R$. festa Vader and Myers, 1996, was described.

Up to date there are nine known species of Ruffojassa, including the new species described herein. This genus has a worldwide distribution and most of its species inhabit shallow waters, 0-130 m depth (Barnard and Karaman, 1991). Some species of Ruffojassa have been recorded in association with other invertebrates, such as hermit crabs, e.g. Strigopagurus strigimanus (White, 1847), Diacanthurus spinulimanus (Miers, 1876) and Paguristes barbatus (Ortmann, 1892) (Moore,
1985; Vader and Myers, 1996). In this paper we describe a new species, Ruffojassa petronioi sp. nov., which also represents a new record of the genus from Brazilian waters.

\section{Material and Methods}

Appendages and mouthparts are mounted on glass slides and sealed with glycerol gel after staining with Chlorazol Black. Type material is deposited in the Museu de Oceanografia - Petrônio Alves Coelho/Universidade Federal de Pernambuco (MOUFPE). The illustrations were drawn under a compound microscope with a camera lucida and digitally inked using the methods of Coleman (2003). The body length of the specimens is given in millimeters $(\mathrm{mm})$. The crustacean spines and setae classification follows Watling (1989). The nomenclature of the gnathopod palm is based on Poore and 
Lowry (1997). The following abbreviations are used in the figures: Ep, epistome; Gn, gnathopod; HA, habitus; LL, lower lip; Md, mandible; Mx, maxilla; Mxp, maxilliped; $\mathrm{P}$, pereopod; T, telson; Ur, uropod; m, male; $\mathrm{f}$, female.

Results

\section{Systematics}

Order Amphipoda Latreille, 1816

Suborder Corophiidea Leach, 1814

Family Ischyroceridae Stebbing, 1899

Genus Ruffojassa Vader and Myers, 1996

Diagnosis: Accessory flagellum absent. Coxa 1 not obscured by coxa 2 . Coxa 2 , in male, broader than deep. Coxa 4 unexcavate posteriorly. Coxa 5 anterior lobe very large, as deep as coxa 4, posterior lobe very small. Uropod 3 peduncle with several long wiresetae on outer margin, outer ramus straight with single distal unhooked spine or lacking spine. Telson lacking cusps (Vader and Myers, 1996).

Generic composition: $R$. andromedae (Moore, 1985); $R$. angularis (Shoemaker, 1942); R. chikoa (Griffith, 1974); R. festa Vader and Myers, 1996; $R$. georgiana (Schellenberg, 1931); ?R. longicephalus (Ledoyer, 1978); $R$. petronioi sp. nov.; $R$. spinipalma (Ledoyer, 1979); R. tristanensis (Stebbing, 1888).

\section{Ruffojassa petronioi sp. nov.}

(Figs. 1-3)

Material examined: Holotype, male, 5.2 mm, St. MBT 161, 21042'S / 40¹5'W, mini biological trawl (MBT), $56 \mathrm{~m}, 6$ September 1970, R.V. Prof. W. Besnard col., MOUFPE 15010. Paratypes. 1 male, $4.8 \mathrm{~mm}$ (dissected and drawn), St. MBT 161, 21042'S / 40¹5'W, mini biological trawl, 56 m, 6 September 1970 , R.V. Prof. W. Besnard col., MOUFPE 15011. 3 males, St. MBT 161, 21042'S / 40¹5'W, mini biological trawl, 56 m, 6 September 1970 ,
R.V. Prof. W. Besnard col., MOUFPE 15012. 1 female, $3.5 \mathrm{~mm}$ (dissected and drawn), St.

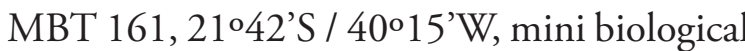
trawl, 56 m, 6 September 1970, R.V. Prof. W. Besnard col., MOUFPE 15013.

Etymology: Named in honor to Dr. Petrônio Alves Coelho (Department of Oceanography, Federal University of Pernambuco) for his great contribution to the knowledge on the crustacean fauna from the Brazilian coast.

Diagnosis: Head with very prominent lateral cephalic lobes. Antenna 2 accessory flagellum absent. Gnathopod 1 of male with dactylus as long as palm. Gnathopod 2 of male with palm oblique with 2 shallow sinuses, defined by a small spine. Pereopod 5 basis with a row of plumose setae on anterior margin. Uropods 1 and 2 with 3 long setae on outer margin. Telson with one lateral simple setae on each side.

Description: Head shorter in length than the first two pereonites combined; lateral cephalic lobes very prominent, anteroventral margin deeply regressed, eye of moderate size, occupying the lateral lobes of the head. Antenna 1 shorter and more slender than antenna 2, bearing long setae on posterior margin, mainly on peduncular article 1 and 2, peduncular article 2 twice as long as article 1, peduncular article $30.8 \mathrm{X}$ of peduncular article 2 length; flagellum 7-articulate. Antenna 2 peduncular article $51.3 \mathrm{X}$ longer than article 4; flagellum 5 -articulate, article 1 equal in length to others combined. Epistome strongly produced into an acute projection. Lower lip with large inner lobes. Mandible incisor 2-dentate, lacinia mobilis 3-dentate, 3 accessory spines present; palp elongate, article $21.2 \mathrm{X}$ longer than article 3 with media and lateral setae, article 3 spatulate, with a row of long plumose setae. Maxilla 1 inner plate small, triangular and naked; outer plate with 7 serrate robust setae; palp 2-articulate, article 2 with 6 apical robust setae and 4 sub-apical setae. Maxilla 2 outer plate broader than inner plate, both apically 


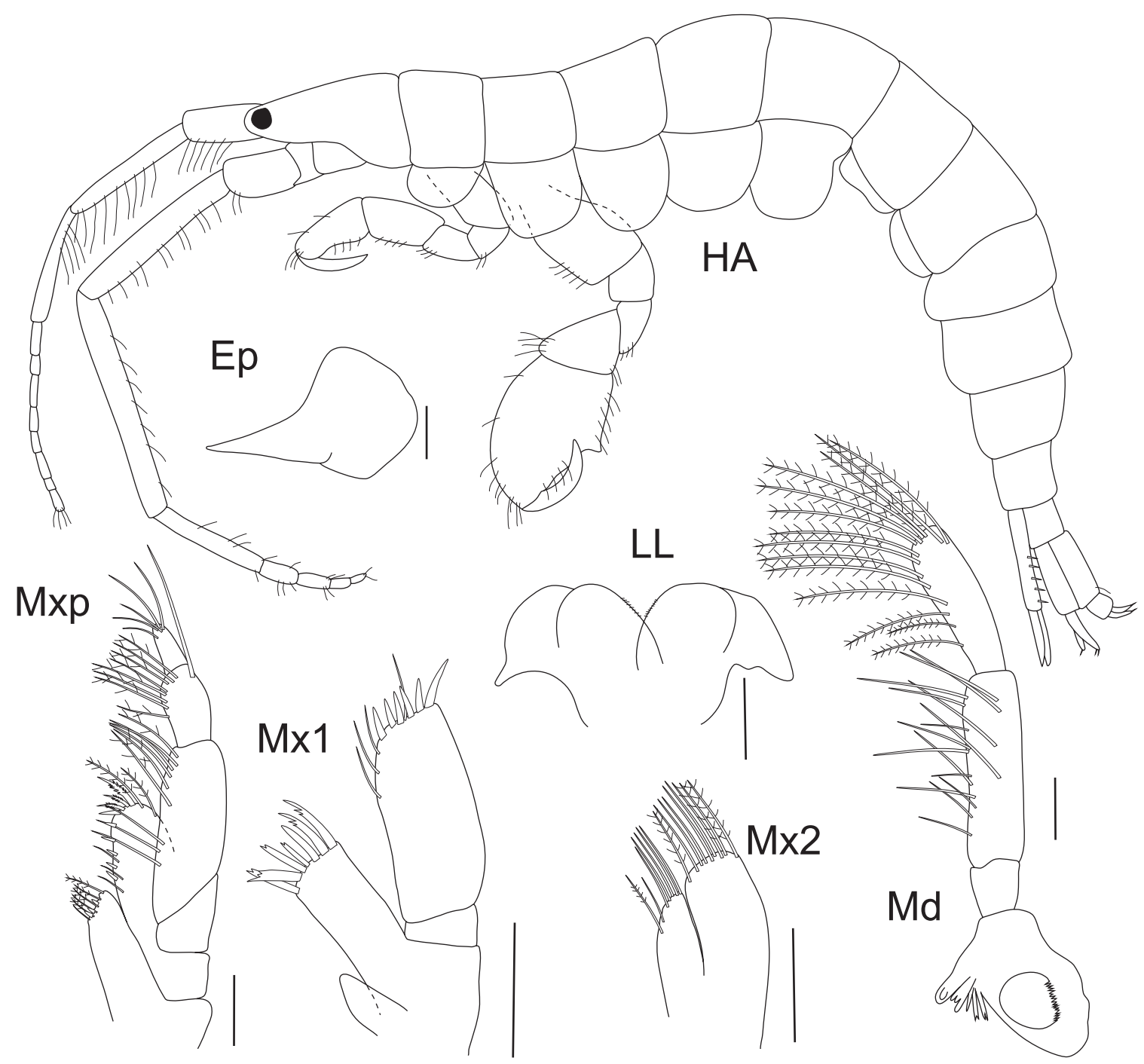

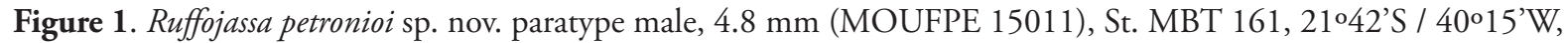
$56 \mathrm{~m}, 6$ September 1970, R.V. Prof. Wladimir Besnard. Scale bars $=0.1 \mathrm{~mm}$.

setose. Maxilliped inner plate rectangular, shorter than half of the outer plate, with 3 apical robust setae and 6 apical pinnate setae; inner plate reaching over half way along article 2 of palp, with 5 robust setae along medial margin and 4 pinnate setae and 2 plumose setae on distal margin; palp 4-articulate, article $22.5 \mathrm{X}$ longer than article 3 , both articles with a row of setae on inner margin, article 4 with apical setae.

Gnathopod 1 subchelate, coxa not produced forwards, about as broad as long; basis moderately stout, $2 \mathrm{X}$ longer than wider, with a long seta on posterior margin; carpus $0.7 \mathrm{X}$ propodus length, with a row of single simple setae on posterior margin; propodus narrower distally, posterior margin shorter than palm, palm slightly excavate and crenulate, with short pinnate and long simple setae, palmar corner defined by short triangular process; dactylus fitting palm, with inner margin serrate. Gnathopod 2 subchelate, longer and stronger than gnathopod 1, coxa $1.4 \mathrm{X}$ wider than long; basis moderately stout, 2.5X longer than wide, medial margin with a row of long setae, anterodistal angle produced into a rounded lobe; ischium quadrate, medial margin with a row of long setae; merus slightly longer than ischium, densely setose medially; carpus triangular in shape, with long setae on both anterodistal and posterodistal margins, densely setose medially; propodus elongate, 


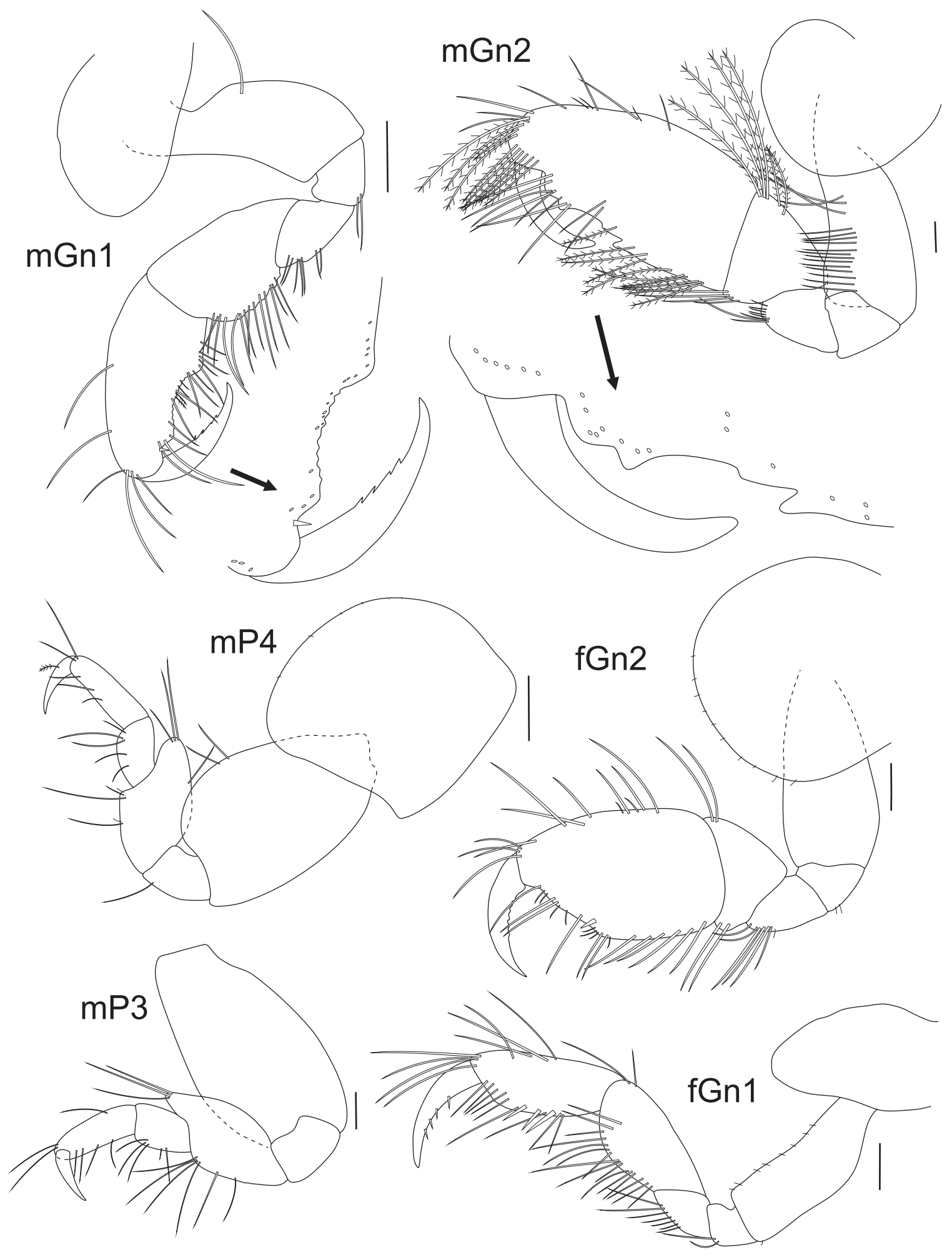

Figure 2. Ruffojassa petronioi sp. nov. paratype male, $4.8 \mathrm{~mm}$ (MOUFPE 15011) and female, $3.5 \mathrm{~mm}$ (MOUFPE 15013), St. MBT 161, 21042'S / 40¹5’W, 56 m, 6 September 1970, R.V. Prof. Wladimir Besnard. Scale bars = 0.1 $\mathrm{mm}$. 


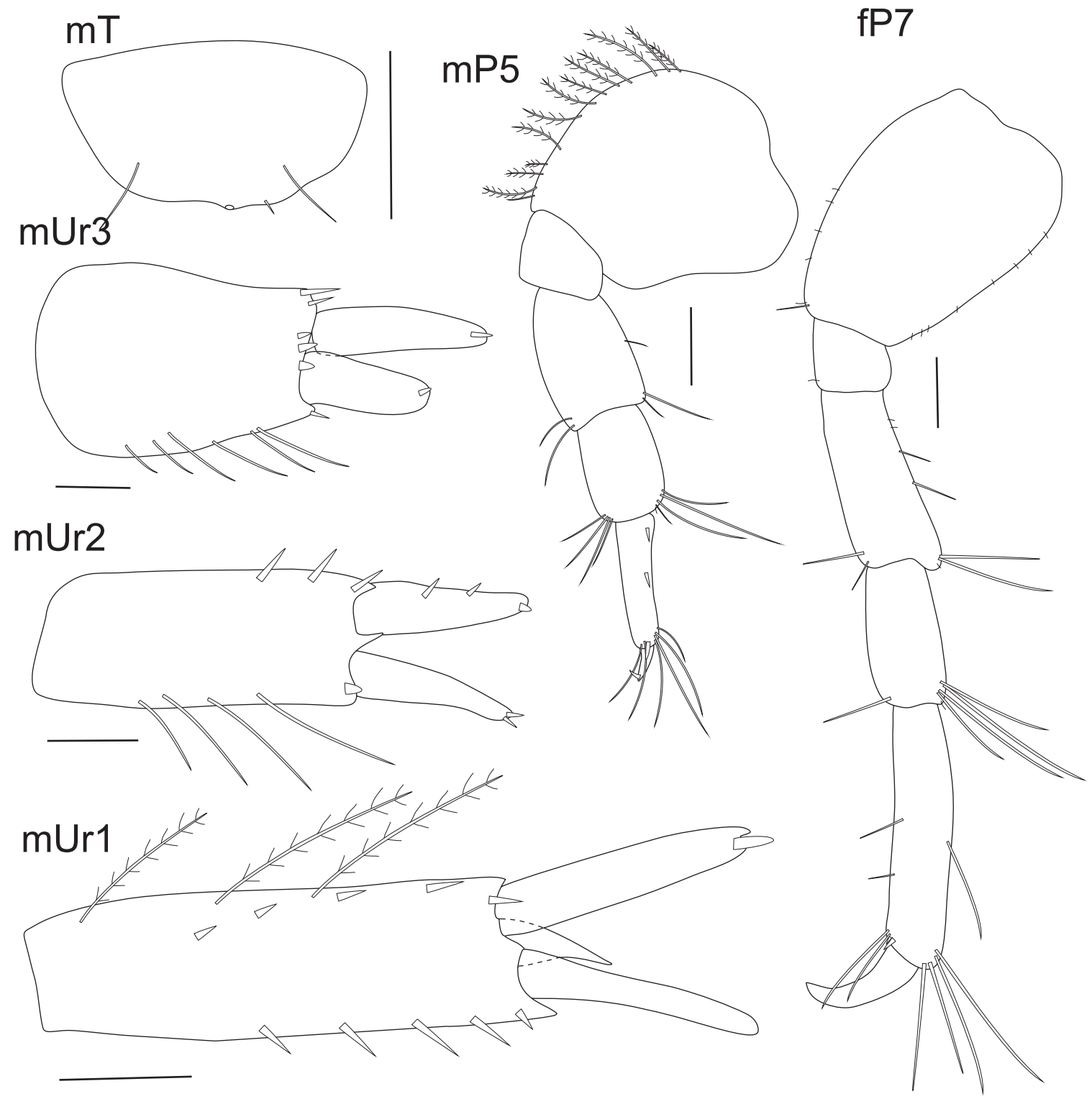

Figure 3. Ruffojassa petronioi sp. nov. paratype male, $4.8 \mathrm{~mm}$ (MOUFPE 15011) and female, $3.5 \mathrm{~mm}$ (MOUFPE 15013), St. MBT 161, 2142'S / 40¹5'W, 56 m, 6 September 1970, R.V. Prof. Wladimir Besnard. Scale bars = 0.1 $\mathrm{mm}$.

ovoid, 1.9 X longer than wide, anterior margin with simple and plumose setae, posterior margin longer than palm, with long plumose setae, densely setose medially; palm acute, with a bifid process near hinge of dactylus and another small process near palmar corner separated by a weakly excavated area; palmar corner defined by a subacute spine; dactylus robust, curved, inner margin smooth and almost reaching end of palm. Pereopods 3 and 4 similar in shape and ornamentation, bases about $1.7 \mathrm{X}$ longer than wide; merus expanded with an anteroventral rounded lobe reaching of middle of carpus. Pereopod 5 basis with a row of plumose setae on anterior margin; propodus with 2 robust setae on anteromedial margin and 1 apical robust seta; dactylus short with 1 apical robust setae. Pereopods 6 and 7 missing.

Epimera 1-3 posteroventral margin rounded. Uropod 1 peduncle $1.3 \mathrm{X}$ longer than rami, with row of robust setae along both margins, outer margin with 3 plumose setae, apical margin with 1 large interramal spine; inner ramus with 1 apical robust seta; outer ramus naked. Uropod 2 peduncle $2 \mathrm{X}$ longer than rami, with 3 robust setae on outer margin 
and 4 long simple setae on inner margin, apical margin with 1 short spine; outer ramus with 2 robust setae on lateral margin and 1 apical robust seta; inner ramus with 2 apical robust setae. Uropod 3 short, peduncle $1.5 \mathrm{X}$ longer than inner ramus, outer margin with 6 long simple setae, inner margin with 3 apical robust seta, apical margin with 3 robust setae; inner ramus $1.3 \mathrm{X}$ longer than outer ramus, both with apical robust setae. Telson subrectangular, with one lateral simple seta on each side.

Female: $5.5 \mathrm{~mm}$. Similar to the male except for the gnathopods which are shorter and more slender. Gnathopod 1 propodus with 3 robust setae along posterior margin, palmar angle not defined. Gnathopod 2 less setose than male, palm defined by 1 short robust seta and.

Remarks: Ruffojassa petronioi sp. nov. resembles $R$. andromedae sharing with that species the oblique palm defined by a spine of the male gnathopod 2 and long setae on anterior margin of basis of pereopod 5. However, the new species differs of $R$. andromedae in the very prominent lateral cephalic lobes, dactylus of male gnathopod 1 as long as palm, male gnathopod 2 palm acute with a bifid process near hinge of dactylus and another small process near palmar corner separated by a poorly excavated area and palmar corner defined by a subacute spine, peduncles of uropods 1 and 2 with few setae along outer margin and telson with only simple setae. Ruffojassa festa shares with the new species the very prominent lateral cephalic lobes, long setae on the basis of pereopod 5 and the presence of few long setae on outer margin of peduncles of uropods 1 and 2, but the former can be distinguished from it by the palm of both gnathopods of male defined by a process or a spine, the longer interramal spine on uropod 1, a lack of constriction on outer ramus of uropod 2 and ornamentation of telson.

Geographic distribution: Only know from type locality (21042'S / 40¹5’ W) (Fig. 4).
Depth range: The specimens studied herein were collected at $56 \mathrm{~m}$ depth.

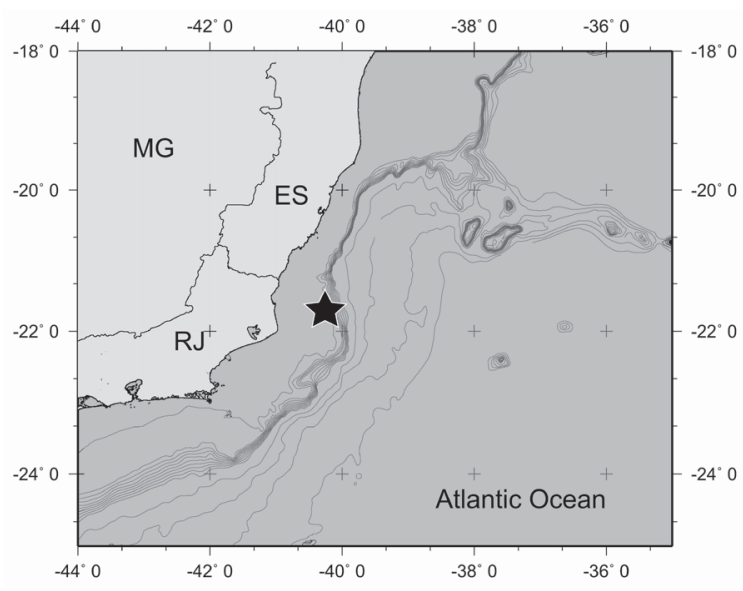

Figure 4. Ruffojassa petronioi sp. nov. Type locality, St. MBT 161, 21042'S / 40¹5’W, 56 m, 6 September 1970, R.V. Prof. Wladimir Besnard. RJ = Rio de Janeiro, $\mathrm{MG}=$ Minas Gerais, ES = Espírito Santo.

\section{Acknowledgments}

The Coordenação de Aperfeiçoamento de Pessoal de Nível Superior (CAPES) and Fundação de Amparo à Ciência e Tecnologia do Estado de Pernambuco (FACEPE) are thanked for the first author's fellowship (Edital 2010/1).

\section{References}

Barnard, J.L. and Karaman, G.S. 1991. The families and genera of marine gammaridean Amphipoda (except marine gammaroids). Records of the Australian Museum, Supplement 13(1-2): 1-866.

Coleman, C.O. 2003. "Digital inking": How to make perfect line drawings on computers. Organisms, Diversity and Evolution, 3 (Electronic Supplement 14): 1-14.

Moore, P.G. 1985. A new deep water species of Amphipoda (Crustacea) discovered off Otago, New Zealand and a note on another little known species. Zoological Journal of 
the Linnean Society, 83: 229-240.

Poore, A.G.B. and Lowry, J.K. 1997. New amphithoid amphipods from Port Jackson, New South Wales, Australia (Crustacea: Amphipoda: Ampithoidae). Invertebrate Taxonomy, 11: 897-941.

Vader, W. and Myers, A.A. 1996. Amphipods living in association with hermit crabs in S.E. Australia. I. Five new Ischyroceridae. Bollettino del Museo Civico di Storia Naturale di Verona, 20: 263-292.

Watling, L. 1989. A classification of crustacean setae based on the homology concept. p. 15-26. In: B.E. Felgenhauer, L. Watling and A.B. Thistle (eds), Functional Morphology of Feeding and Grooming in Crustacea. Crustacean Issues, Vol. 6. Rotterdam, A.A. Balkema. 